\title{
Computerized history-taking as a tool to manage dyslipidemia
}

This article was published in the following Dove Press journal:

Vascular Health and Risk Management

II November 2010

Number of times this article has been viewed

\author{
David Zakim' \\ Christine Fritz ${ }^{2}$ \\ Niko Braun ${ }^{1,3}$ \\ Peter Fritz' \\ M Dominik Alscher ${ }^{1,3}$ \\ 'Institute for Digital Medicine, \\ Stuttgart, Germany; ${ }^{2}$ University of \\ Ulm, Ulm, Germany; ${ }^{3}$ Robert Bosch \\ Krankenhaus, Stuttgart, Germany
}

Correspondence: David Zakim Institute for Digital Medicine, Am Kreigsburgturm 44, Stuttgart, Germany 70192

Tel +49 4I5-462-1759

Fax +49 4I5-462-1759

Email dzakim@pacbell.net
Background: Validated guidelines to manage low-density lipoprotein (LDL)-cholesterol are utilized inconsistently or not at all even though their application lowers the incidence of coronary events. New approaches are needed, therefore, to implement these guidelines in everyday practice.

Methods and results: We compared an automated method for applying The National Cholesterol Education Panel (NCEP) guidelines with results from routine care for managing LDL-cholesterol. The automated method comprised computerized history-taking and analysis of historical data without physician input. Results from routine care were determined for 213 unselected patients and compared with results from interviews of the same 213 patients by a computerized history-taking program. Data extracted from hospital charts showed that routine care typically did not collect sufficient information to stratify risk and assign treatment targets for LDL-cholesterol and that there were inconsistencies in identifying patients with normal or elevated levels of LDL-cholesterol in relation to risk. The computerized interview program outperformed routine care in collecting historical data relevant to stratifying risk, assigning treatment targets, and clarifying the presence of hypercholesterolemia relative to risk.

Conclusions: Computerized history-taking coupled with automated analysis of the clinical data can outperform routine medical care in applying NCEP guidelines for stratifying risk and identifying patients with hypercholesterolemia in relation to risk.

Keywords: dyslipidemia, coronary disease, prevention, management, computerized-history taking

Coronary artery disease is the leading cause of death in the developed world. ${ }^{1}$ Fortunately, risk for coronary events can be mitigated by lowering concentrations of low-density lipoprotein (LDL)-cholesterol that have been shown in large-scale epidemiologic studies to enhance risk for an event. ${ }^{2-8}$ Despite, however, the high incidence of a lethal event and evidence that its risk can be decreased, there is poor adherence in everyday practice to guidelines for managing dyslipidemia or elevated levels of LDL-cholesterol in order to decrease risk for coronary events. ${ }^{9-16}$ Kuklina et al ${ }^{16}$ suggest that general failure to diminish risk for coronary events by applying National Cholesterol Education Program (NCEP) guidelines to reduce LDL-cholesterol ${ }^{6}$ reflects the complexity of the guidelines. A recent editorial in the Journal of the American Medical Association characterized the guidelines as “... cumbersome and a challenge to implement". ${ }^{17}$ Several ideas have been proposed to simplify guidelines for managing LDL-cholesterol, but most retain assessment of risk from sets of detailed clinical data. ${ }^{17-19}$ Given the relatively large number of patients who must be treated to prevent a single coronary event, ${ }^{20-22}$ it is reasonable to posit that more not less knowledge needs 
to be applied to assessing risk. More medical knowledge, of course, will increase the complexity of risk-assessment in everyday practice; and inevitable growth in the classes of drugs that lower LDL-cholesterol will increase further the complexity of treatment decisions. ${ }^{23}$ Simplifying current guidelines to get better clinical outcomes is unlikely, therefore, to be effective in the long-run. We thus need alternative mechanisms to enhance patient outcomes through adherence to validated clinical guidelines.

Computers can be programmed to acquire the detailed historical data for assessing risk for coronary events, ${ }^{24-26}$ to score the historical factors according to any risk equation, and to output the data for interpretation and review by the health care provider. So in theory, a properly designed computer program interacting directly with patients should be able to collect primary data for applying NCEP guidelines, interpret these data accurately to assign level of risk, and recommend treatment in the context of risk-related targets for treating LDL-cholesterol. This is an attractive area for study because of the medical significance of coronary artery events and because there are effective treatments to reduce risk for an event that go largely unused. ${ }^{9-16}$ Moreover, clinical details in the patient's medical history are the key data elements for implementing the NCEP guidelines; and the guidelines are clear-cut and easily formalized as machine-readable code. We have tested these ideas in the current work and report here on the use of computing to assess risk for coronary events and set therapeutic targets for LDL-cholesterol, according to NCEP guidelines, through direct interaction between computers and patients in the absence of inputs by health care providers. Comparisons of outputs from the computer program used in this way with charts for usual care show that the computer program outperforms physicians in the tasks of data collection to assess risk, assigning risk according to NCEP guidelines, and diagnosing dyslipidemia on the basis of the guidelines.

\section{Methods}

\section{Software and deployment}

The design principles, ownership, medical content, and deployment of the software comprising the CLEOS $^{\circledR}$ program are presented in detail elsewhere. ${ }^{26}$ Questions used to interview patients were formatted by experienced clinicians in different domains of medicine and were based on standard text book formulations for acquiring information about the presence and absence of specific sets of symptoms, relationships between symptoms according to principles of pathophysiology, clinically relevant information related to risks for disease, prior and present treatments for disease, social history, and family history. As shown in detail in Zakim et al, ${ }^{26}$ questions were arranged as decision graphs based on pathophysiologies for diseases of different organ systems.

Computerized history-taking in the present work was not focused on data elements relevant only to risks for coronary events. Complete medical histories were obtained from all patients interviewed. Data elements relevant to application of NCEP guidelines were evaluated automatically by an internal inference engine to output findings for risk level in relation to targets for treating LDL-cholesterol.

\section{Patients}

Patients were in-patients in the departments of Internal Medicine and Cardiology at the Robert Bosch Krankenhaus, Stuttgart, Germany. Ages of patients ranged from 20 to 84 with a median of 51 years. Males comprised $54 \%$ of the study group. A single study nurse was responsible for recruiting patients. The nurse had no prior knowledge of a patient's primary and secondary diagnoses or the purpose of data collection and eventual data analysis. The study nurse did not record demographic data, admitting diagnoses, or severity of current illness for any patient entered in the study or for patients who declined to participate. Sixteen different physicians provided routine care for the patients for whom data are reported in this work. Patients were not recruited on the basis of physicians responsible for in-hospital care, gender, age, or prior experience with computers. None of the authors was involved in recruiting patients for the interview nor did any hospital physicians participate in recruitment. The criteria for inclusion in this study were patient-consent for interview by the CLEOS ${ }^{\circledR}$ program and reading knowledge of German or English. No patient who agreed to participate had to be excluded because of inability to read one of these languages. Ten patients declined interview by the computer program. Data for these patients are not included in this study. All patients who agreed to participate in the program entered a complete medical history via the computerized interview. Ethics approval for this study was waived by the ethical board of the University of Tuebingen.

\section{Data collection}

Standard physician histories, designated here as routine care, were taken on admission by each patient's responsible physician. Patients subsequently self-interviewed using the CLEOS $^{\circledR}$ program, ${ }^{26}$ which acquired a present illness, review of systems, past medical history, current medications, 
social history, and family history. We note that this study was designed with a single cohort of patients. Clinical data in the chart for routine care for each patient in this study were compared with clinical data from computer-generated outputs of the CLEOS ${ }^{\circledR}$ program for the same patient. All patients were German-speaking and were interviewed by the German-language version of the CLEOS $^{\circledR}$ program. Patients self-interviewed on their ward or the office of the study nurse after routine history-taking was completed by their responsible physician and when interviews by the CLEOS ${ }^{\circledR}$ program did not interfere with other aspects of routine care. The computerized interview was conducted usually on the same day or within 2 days of the admission history for routine care. Reports from CLEOS ${ }^{\circledR}$ interviews were not made available to physicians caring for patients. No treatment decisions were undertaken or reviewed because of data collected by the $\mathrm{CLEOS}^{\circledR}$ interview.

\section{Data extraction from charts for routine care}

The data fields extracted from charts were those used by NCEP guidelines to characterize risk for coronary events, for example, the presence of diabetes, history of angina, history of peripheral vascular disease, smoking, hypertension, according to a scale of high, moderate, or low risk and assignment to target levels of LDL-cholesterol $\leq 100 \mathrm{mg} / \mathrm{dL}$ (high risk), $\leq 130 \mathrm{mg} / \mathrm{dL}$ (moderate risk), or $\leq 160 \mathrm{mg} / \mathrm{dL}$ (low risk). ${ }^{1}$ Charts for routine care were read to tabulate the presence or absence of relevant data fields, for the presence of explicit statements of level of risk and target levels of LDL-cholesterol, and to tabulate entries about present or past treatment to reduce LDL-cholesterol. Review and data extraction extended across the chart for the entire period of each patient's hospitalization. In addition, all discharge letters to referring physicians were reviewed to search for clinically relevant data possibly not recorded in the hospital chart but known to a patient's responsible physician. Tabulations of data for routine care did not discriminate between data obtained from a chart and data obtained from a discharge letter. Since no chart for routine care contained statements about level of risk or targets for LDL-cholesterol (See results), evaluation of charts for routine care for consistency between clinical data and assignment of level of risk had no meaning. We did not plan a priori to determine whether a patient at moderate risk by historical data was at high enough risk to warrant a target of $\leq 100 \mathrm{mg} / \mathrm{dL}$ on the basis of combined clinical and laboratory data. This decision was made because the computer-based program did not include on-line acquisition of laboratory data at the time computer-based interviews were conducted. As indicated in the results, the general absence of sufficient data for assigning patients to a level of moderate risk by historical criteria made meaningless any subclassification within this group. Values of LDL-cholesterol were measured at the Robert Bosch Krankenhaus during the hospitalization for which the chart for routine care and the CLEOS ${ }^{\circledR}$ interview were generated.

Charts for routine care were extracted independently by $\mathrm{CF}, \mathrm{NB}$, and MDA. Fifty charts at random were reviewed independently by both CF and NB. No discrepancies were found between reviewers in this subset of 50 charts. Data tabulated from charts for routine care were analyzed by DZ to assign a level of risk and a target for LDL-cholesterol according to NCEP guidelines.

\section{Data extraction from computerized-history-taking}

The CLEOS $^{\circledR}$ program collects historical information by direct interview of the patient and automatically analyzes these data to stratify risk and output a target for LDL-cholesterol appropriate for level of risk. Figure 1 is an example of an output relevant to NCEP guidelines for LDL-cholesterol. Outputs from the CLEOS ${ }^{\circledR}$ program were read to tabulate target levels for LDL-cholesterol and were examined patient-by-patient for consistency between assigned targets for LDL-cholesterol and recorded clinical data for assigning the target according to the NCEP guidelines. Since, as mentioned above, the version of the CLEOS $^{\circledR}$ program used in the current work did not include online acquisition of laboratory fields, NCEP guidelines applied to data analysis excluded laboratory values for total cholesterol and high-density lipoprotein (HDL)-cholesterol for either routine care or computer history. Extraction of $\mathrm{CLEOS}^{\circledR}$ records was done by DZ.

\section{Results \\ History-taking and decision-making to stratify risk for coronary events according to NCEP guidelines}

Two tasks must be completed to mitigate risk for coronary events through managing concentrations of LDL-cholesterol according to NCEP guidelines. The first is collecting the clinical data required by the guidelines for stratifying risk as high (LDL-cholesterol target of $\leq 100 \mathrm{mg} / \mathrm{dL}$ ), moderate (LDLcholesterol target of $\leq 130 \mathrm{mg} / \mathrm{dL}$ ), or low (LDL-cholesterol 
- On the basis of historical data, the LDL-cholesterol $<130$ is minimal target in this patient because of age and active smoking. Further reduction of risk in patients with this risk profile is achieved with LDL-cholesterol $<=100$. Patient should stop smoking, but this will not alter current target value for LDL cholesterol. The patient's risk for CAD/stroke has to be stratified further by systolic BP, total cholesterol and HDL-cholesterol. Once these are entered, the program will calculate whether risk for $C A D=>20 \%$ over 10 years, in which case maximum preventive benefit is achieved at LDL-cholesterol $=<70$.

Figure I Sample text of output by the CLEOS ${ }^{\circledR}$ program for reporting stratification of risk for a coronary event and target for treating LDL-cholesterol.

target of $\leq 160 \mathrm{mg} / \mathrm{dL}$ ). The second is assigning a target for LDL-cholesterol that is appropriate to the level of risk identified by the clinical data.

Two hundred thirteen medical records for routine care and CLEOS ${ }^{\circledR}$ interviews for the same set of 213 unselected patients were reviewed to evaluate performance of these tasks by physicians and the CLEOS ${ }^{\circledR}$ program. Results are summarized in Table 1. Review of charts for routine care demonstrated insufficient clinical data to assign a level of risk in $70 \%$ of patients and an absence of explicit statements for level of risk in all charts. Clinical data collected during routine care were sufficient to assign any level of risk for coronary events in 64 patients, of whom 57 could be assigned to high risk. Of the 149 charts for routine care with insufficient data to assign any level of risk, it was possible to exclude high risk for coronary events in only 12 patients.

The CLEOS $^{\circledR}$ program identified 81 patients at high risk for a coronary event on the basis of history. Differences in the number of high-risk patients recorded in charts for routine care and CLEOS ${ }^{\circledR}$ were due to better case finding by CLEOS ${ }^{\circledR}$ for patients with past histories of bypass surgery, angioplasty, myocardial infarction, and peripheral vascular disease.

The group of high-risk patients identified by CLEOS ${ }^{\circledR}$ interviews does not include 6 patients at high risk by data in charts for routine care on the basis of transient ischemic attacks (1 patient), coronary artery disease (1 patient), and diabetes (4 patients). For the patient with transient ischemic attacks according to the chart for routine care, the CLEOS ${ }^{\circledR}$ program reported this patient had a moderate risk for a coronary event because of age and hypertension and assigned a target level for LDL-cholesterol of $130 \mathrm{mg} / \mathrm{dL}$. The output of the CLEOS ${ }^{\circledR}$ program for this patient qualified risk assignment with an alert to reclassify the patient to high risk if the patient's neurologic symptoms were attributable to transient ischemic attacks. For the patient with coronary artery disease according to the chart for routine care, the CLEOS ${ }^{\circledR}$ program assigned the patient to the group with moderate risk with an alert to reclassify to high risk if the patient's chest pain was verified as angina. These 2 patients are reported for the $\operatorname{CLEOS}^{\circledR}$ data as instances of a target of $130 \mathrm{mg} / \mathrm{dL}$ to be consistent with reporting conclusions derived from the CLEOS $^{\circledR}$ interview only on the basis of historical data available at admission. Including these patients, the CLEOS $^{\circledR}$ chart identified all patients at high risk in data in charts for routine care except for a subgroup with diabetes.

Four patients with diabetes, according to the chart for routine care or discharge letter, answered they did not have diabetes when asked this question during the CLEOS ${ }^{\circledR}$ interview. Assignment of these patients to LDL-cholesterol targets of $130 \mathrm{mg} / \mathrm{dL}$ was incorrect for failure in data collection but was consistent internally with the data collected by CLEOS $^{\circledR}$. These patients are cited in Table 1 as instances of errors/omissions in data collection by the CLEOS ${ }^{\circledR}$ program. The false negative findings for diabetes were detected by monitoring of discrepancies between routine care and historytaking by $\mathrm{CLEOS}^{\circledR}$ in the time before data analysis related to coronary risk was undertaken. These failures to detect the presence of diabetes with the CLEOS $^{\circledR}$ interview occurred with a question that queried the absence/presence of diabetes as 1 line in a questionnaire. We concluded that the question about prior diagnosis of diabetes was not read carefully in this format and modified the query about presence/absence of diabetes as the only question on the page. Subsequent to this change, the CLEOS ${ }^{\circledR}$ program properly identified 11 diabetics, all of whom could be identified as diabetic in charts for routine care or discharge letters on the basis of explicit statements related to medical history, elevated fasting blood sugar, and/or administration in hospital of hypoglycemic agents.

The group of high-risk patients identified by CLEOS $^{\circledR}$ interview but not routine care included 4 with historical evidence of intermittent claudication in the absence of diabetes, prior coronary events, or other evidence for atherosclerotic disease. Review of the primary data collected by CLEOS ${ }^{\circledR}$ for these patients confirmed that intermittent claudication was the best working diagnosis to explain effort-induced leg pain relieved promptly by rest. Review of the primary data in the output of the computerized interview of these patients 
Table I Comparison of assigned levels of risk for coronary disease and completeness of data for assigning risk for clinical data extracted from charts for routine care and assignments of risk output automatically by the CLEOS $^{\circledR}$ program for the same set of 213 patients

\begin{tabular}{|c|c|c|}
\hline Level of risk & $\begin{array}{l}\text { Assigned from charts } \\
\text { for routine care }\end{array}$ & $\begin{array}{l}\text { Output in } \\
\text { CLEOS }^{\circledR} \text { report }\end{array}$ \\
\hline High risk with target $\leq 100$ & 57 & 81 \\
\hline Target $\leq 130$ & 3 & 54 \\
\hline Target $\leq 160$ & 4 & 74 \\
\hline Data sufficient to exclude high risk & 12 & 128 \\
\hline Explicit statement of target for LDL-cholesterol & 0 & 209 \\
\hline Data sufficient to assign risk but error in interpretation & NA & 4 \\
\hline Errors/omissions in data collection & 146 & 4 \\
\hline
\end{tabular}

Notes: Assignments of risk for data from routine charts are based on analysis of primary clinical data extracted from these charts. This was necessary because no chart for routine care contained an assignment of risk. Assignment of risk for data obtained by the CLEOS ${ }^{\circledast}$ program are the treatment targets assigned through automated analysis by $\mathrm{CLEOS}^{\circledast}$ of the clinical data collected by the program.

Abbrevation: NA, not applicable.

did not support alternative diagnoses of spinal stenosis or venous insufficiency. Obviously, however, symptoms compatible with intermittent claudication require objective support through physical examination and objective testing before undertaking a management decision to treat the affected patients as at high risk for coronary events. Historical evidence for claudication in charts for routine care was not mentioned as positive or negative for these patients. The charts for routine care lacked physical examination data for the presence or absence of peripheral pulses or other signs of peripheral vascular insufficiency. No laboratory testing was undertaken in these patients to confirm the presence of intermittent claudication. The diagnosis of intermittent claudication thus was not confirmed objectively in these patients. The value of CLEOS ${ }^{\circledR}$ for care of these patients was in identifying an important rule-out diagnosis for management of coronary risk, which was missed by routine care.

The CLEOS ${ }^{\circledR}$ program failed to report an explicit target for LDL-cholesterol in 4 patients. The clinical data collected by CLEOS $^{\circledR}$ for these 4 patients nevertheless correctly excluded high risk for coronary disease and were sufficient to assign targets for LDL-cholesterol of 130 or $160 \mathrm{mg} / \mathrm{dL}$. Failure to report a target for these 4 patients was traced to logic errors in rules triggering appropriate outputs of a narrative text.

\section{Diagnosis of hypercholesterolemia according to guidelines and treatment decisions}

Physicians, to save time, do not always document the evidence for clinical decisions, for example, that a patient is or is not at high risk for a coronary event. It is significant in this context that discharge letters but not the corresponding charts cited 39 patients as hypercholesterolemic at the time of discharge. Comparison of concentrations of LDLcholesterol during hospitalization with target levels for LDL-cholesterol determined from data collected by CLEOS ${ }^{\circledR}$ indicated, however, that 21 of the patients diagnosed with hypercholesterolemia were at or below target levels for LDLcholesterol, and no measurement of cholesterol was available in 4 others. By contrast, levels of LDL-cholesterol in excess of targets according to NCEP guidelines were not recognized in about $70 \%$ of patients with hypercholesterolemia. Statin therapy was initiated during hospitalization in 22 patients, based on notes in charts for routine care. Fourteen of these patients were not hypercholesterolemic by NCEP criteria.

\section{Discussion}

This work confirms poor adherence to NCEP guidelines for managing elevated levels of LDL-cholesterol. ${ }^{9-16}$ van Wyk et $\mathrm{al}^{27}$ have shown, in this regard, that electronic alerts keyed to data in an electronic medical record can improve adherence to the guidelines. The current work extends the findings in the literature in general and the work of van Wyk et $\mathrm{a}^{27}$ in particular by indicating that failure to interpret or understand clinical data collected from the patient is only part of the problem of compliance with NCEP guidelines. There also is frequent failure to acquire sufficient clinical data for assigning level of risk according to NCEP guidelines. This is important to recognize considering recent thinking of how to improve outcomes for people at risk for coronary events. One suggestion, for example, is to treat with statins everyone at greater than low risk. ${ }^{17}$ Although apparently simple, this guideline is unlikely to work in practice because, as the current work illustrates, clinical data are typically inadequate for assessing risk. In the current work, for 
example, there were insufficient clinical data for classifying patients at high or moderate risk.

The present work illustrates an alternative to simplifying or even dumbing-down guidelines for managing LDLcholesterol. The present work shows that a computerized history-taking program interacting directly with patients can collect sufficient clinical data to implement NCEP guidelines for assigning risk and that combined computerized data collection and automatic, computerized data analysis within a single technology, enables automated computer-based analysis of the historical data in the context of established guidelines to output findings as simple explicit statements of risk levels and targets for managing LDL-cholesterol (Figure 1). These simple statements about target levels can be compared directly with measured levels of LDLcholesterol to determine whether or not the patient has LDL-cholesterol that is elevated for their risk of coronary events. History-taking and analysis in this way can not only save physician time for collecting data, it can also outperform physicians in this important facet of practice. It also makes it possible to incorporate refinements in predictive algorithms that will make it harder for people but not computers to use enhanced guidelines.

The version of CLEOS $^{\circledR}$ used in the current work did not incorporate laboratory and physical findings to further stratify patients with a target level of $130 \mathrm{mg} / \mathrm{dL}$ or to factor concentrations of HDL-cholesterol into determination of risk; therefore it did not utilize all features of NCEP guidelines. There were no instances, however, in which physicians used these features of the guidelines; and compared with teaching to ensure efficient use of these features by physicians in everyday practice, these features can be "taught" easily to a program like $\mathrm{CLEOS}^{\circledR}$, as can functionality for treatment strategies appropriate for individual patients. Further clinical benefit from the approach used in this work is rapid, inexpensive distribution of the primary data and analytic conclusions via the Internet to any physician caring for a patient interviewed by the CLEOS $^{\circledR}$ program. The program also leaves an indelible trail of what it did and did not do in collecting and analyzing the clinical information, which facilitates finding and correcting systematic errors.

\section{Computer-based identification and management of risk for coronary events has general applicability}

Patients in this study were older, had a higher burden of disease than patients in a community setting, and were hospitalized at a single institution. Depending on the patient population and expertise of physicians, there will be differences in the extent of discrepancies between routine care and results from the $\mathrm{CLEOS}^{\circledR}$ program in the context of managing LDL-cholesterol. We would expect no differences between routine care and application of the CLEOS ${ }^{\circledR}$ program for a study carried out in a specialized clinic for diagnosis and management of dyslipidemia. Relatively few patients at risk for coronary events are seen in such specialized clinics, however; and results for routine care in the present work accord with those reported in the literature. ${ }^{9-16,27}$ The evidence indicates, therefore, that the results in the current work have general applicability.

\section{Differences in case-finding between routine care and the $\mathrm{CLEOS}^{\circledR}$ program cannot be attributed to false positive findings}

Patients make mistakes during the computerized interview because they do not understand the question or they make an accidental, unintended selection of an answer. The study nurse observed patients realizing they made an erroneous entry, as follow-up questions were asked and correcting mistakes by using the program's back button. It is important to mention in this regard, that risk factors for coronary events were not determined as positive because of answers to single questions but by a set of consistent answers to a line of questioning determined by established pathophysiology. The chance of false negative findings with CLEOS $^{\circledR}$ is more likely than the chance of false positives because a positive answer about the presence of symptoms or a prior diagnosis opens a line of questions, whereas a negative answer can be at the end of a line of questions. Given that false positive findings would be generated not by deliberate falsification but by random error, the absence of a significant rate of false negatives would be evidence against a significant rate of false positives. We do not see in the present data evidence for false negative findings that cannot be traced to errors in logic as opposed to data-capture, except for the consistent failure to identify the occurrence of diabetes. This error appears to have been caused by poor design of the page querying a prior diagnosis of diabetes.

\section{Conclusions}

A computerized history-taking program coupled with automated analysis of clinical data collected by direct interview of patients can outperform routine medical care for stratifying risk for coronary events that is mitigated by managing levels of LDL-cholesterol, for identifying treatment targets in individual patients, for identifying patients with 
hypercholesterolemia in relation to risk, for selecting patients in whom active management of levels of LDL-cholesterol is indicated, and for identifying statin-induced adverse drug effects past and present.

\section{Authors' contributions}

DZ was responsible for the concept of the CLEOS ${ }^{\circledR}$ program and more specifically for formalizing as computer code the medical knowledge to assess risk for coronary disease. All authors contributed equally to the conception of the study and analysis of the clinical data extracted from charts and CLEOS $^{\circledR}$ interviews. CF, NB and MDA assembled and extracted relevant data from charts for routine care. DZ performed this task for records from CLEOS $^{\circledR}$ interviews. The first draft of this manuscript was written by DZ. All authors contributed to revision of the draft until assembly of the final version.

$\mathrm{CF}$ is the daughter of $\mathrm{PF}$.

\section{Acknowledgments}

The authors acknowledge Katrin Niederstrasser for her support of this work as study nurse for the program. This work was supported by a grant from the Robert Bosch Stiftung, Stuttgart, Germany.

\section{Disclosure}

DZ holds US patent 2008/0177578, which applies to the technology used in the current manuscript.

$\mathrm{DZ}$ is the major contributor to knowledge content of the CLEOS $^{\circledR}$ program. No other author of this manuscript was involved in development or maintenance of the software comprising the CLEOS ${ }^{\circledR}$ program.

No author has received in the last 5 years any reimbursement, fees, funding, or salary from an organization that may gain from publication of this manuscript. No author owns stock or shares in any organization that may gain or lose financially from publication of this manuscript.

There are no other competing interests financial or otherwise.

\section{References}

1. WHO. The Top Ten Causes of Death 2008. www.who.int/mediacentre/ factsheets/fs310_2008.pdf. Accessed 2010 Jun 10.

2. Law MR, Wald NJ, Thompson SG. By how much and how quickly does reduction in serum cholesterol concentration lower risk of ischemic heart disease? BMJ. 1994;308:367-372.

3. Cole TG, Pfeffer MA, Braunwald E. Cardiovascular events and their reduction with pravastatin in diabetic and glucose intolerant myocardial infarction survivors with average cholesterol levels: subgroup analyses in the cholesterol and recurrent events (CARE) trial: the Care Investigators. Circulation. 1998;98:2513-2519.
4. LaRosa JC, He J, Vupputuri S. Effect of statins on risk of coronary disease: a meta-analysis of randomized controlled trials. JAMA. 1999;282:2340-2346.

5. Baigent C, Keech A, Kearney PM, et al. Cholesterol Treatment Trialists' (CTT) Collaborators. Efficacy and safety of cholesterol-lowering treatment: prospective meta-analysis of data from 90056 participants in 14 randomised trials of statins. Lancet. 2005;366:1267-1278.

6. Grundy SM, Cleeman JI, Merz NB, et al. National Heart, Lung, and Blood Institute;American College of Cardiology Foundation; American Heart Association. Implications of Recent Clinical Trials for the National Cholesterol Education Program. Adult Treatment Panel III Guidelines. Circulation. 2004;110:227-229.

7. Brugts JJ, Yetgin T, Hoeks SE, et al. The benefits of statins in people without established cardiovascular disease but with cardiovascular risk factors: meta-analysis of randomised controlled trials. BMJ. 2009; 338:b2376.

8. Johannesson M, Joennsson B, Kjekshus J, Olsson AG, Pedersen TR, Wedel H. Cost effectiveness of simvastatin treatment to lower cholesterol levels in patients with coronary heart disease. Scandinavian Simvastatin Survival Study Group. N Engl J Med. 1997;336:332-336.

9. Abookire SA, Karson AS, Fiskio J, Bates DW. Use and monitoring of "statin" lipid-lowering drugs compared with guidelines. Arch Int Med. 2001;161:53-58.

10. Wang TJ, Stafford RS, Ausiello JC, Chaisson CE. Randomized clinical trials and recent patterns in the use of statins. Am Heart J. 2001;141: 957-963.

11. Phillips LS, Branch WT, Cook CB, et al. Clinical Inertia. Ann Int Med. 2001;135:825-834.

12. Yarzebski J, Bujor CF, Goldberg RJ, Spencer F, Lessard D, Gore JM. A community-wide survey of physician practices and attitudes toward cholesterol management in patients with recent acute myocardial infarction. Arch Intern Med. 2002;162:797-804.

13. Whincup PH, Emberson JR, Walker M, Papacosta O, Thompson A. Low prevalence of lipid lowering drug use in older men with established coronary heart disease. Heart. 2002;88:25-29.

14. Austin PC, Mamdami MM, Juurlink DN, Alter DA, Tu JV. Missed opportunities in the secondary prevention of myocardial infarction: An assessment of the effects of statin underprescribing on mortality. Am Heart J. 2006;151:949-955.

15. Ferrieres J, Gousse ET, Fabry C, Hermans MP; French CEPHEOS Investigators. Assessment of lipid-lowering treatment in France-the CEPHEUS study. Arch Cardiovasc Dis. 2008;101:557-563.

16. Kuklina EV, Yoon PW, Keenan NL. Trends in high levels of lowdensity lipoprotein cholesterol in the United States, 1999-2006. JAMA. 2009;302:2104-2110.

17. Gaziano JM, Gaziano TA. Simplifying the approach to the management of dyslipidemia. JAMA. 2009;302:2148-2149.

18. Hingorani AD, Psaty BM. Primary prevention of cardiovascular disease: time to get more or less personal? JAMA. 2009;302:2144-2145.

19. Clinical guidelines and evidence review for lipid modification. National Collaborating Centre for Primary Care and Royal College of General Practitioners. http://www.nice.org.uk/nicemedia/pdf/ CG67FullGuideline1.pdf. Accessed 2009 Oct 22.

20. Lloyd-Jones DM, Leip EP, Larson MG, et al. Prediction of lifetime risk for cardiovascular disease by risk factor burden at 50 years of age. Circulation. 2006;113:791-798.

21. Simmons RK, Coleman RL, Price HC, et al. Performance of the UK Prospective Diabetes Study Risk Engine and the Framingham Risk Equations in estimating cardiovascular disease in the EPIC-Norfolk cohort. Diabetes Care. 2009;32:708-713.

22. Hippisley-Cox J, Coupland C, Vinogradov Y, et al. Predicting cardiovascular risk in England and Wales: prospective derivation and validation of QRISK2. BMJ. 2008;336:a332.

23. Raal FJ, Santos RD, Blom DJ, et al. Mipomersen, an apolipoprotein B synthesis inhibitor, for lowering of LDL cholesterol concentrations in patients with homozygous familial hypercholesterolaemia: a randomised, double-blind, placebo-controlled trial. Lancet. 2010;375:918-1006. 
24. Bachman JW. The patient-computer interview: a neglected tool that can aid the clinician. Mayo Clin Proc. 2003;78:67-78.

25. Apkon M, Mattera JA, Lin Z, et al. A randomized outpatient trial of a decision support information technology tool. Arch Int Med. 2005;165: 2388-2394.

26. Zakim D, Braun N, Fritz P, Alscher MD. Underutilization of information and knowledge in everyday medical practice: evaluation of a computer-based solution. BMC Med Inform Decis Mak. 2008;8:50.
27. van Wyk JT, van Wijk MAM, Sturkenboom MCJM, et al. Electronic Alerts versus On-Demand Decision Support to Improve Dyslipidemia Treatment. Circulation. 2008;117:371-378.

\section{Publish your work in this journal}

Vascular Health and Risk Management is an international, peerreviewed journal of therapeutics and risk management, focusing on concise rapid reporting of clinical studies on the processes involved in the maintenance of vascular health; the monitoring, prevention and treatment of vascular disease and its sequelae; and the involvement of metabolic disorders, particularly diabetes. This journal is indexed on PubMed Central and MedLine. The manuscript management system is completely online and includes a very quick and fair peer-review system, which is all easy to use. Visit http://www.dovepress.com/ testimonials.php to read real quotes from published authors.

Submit your manuscript here: http://www.dovepress.com/vascular-health-and-risk-management-journal 